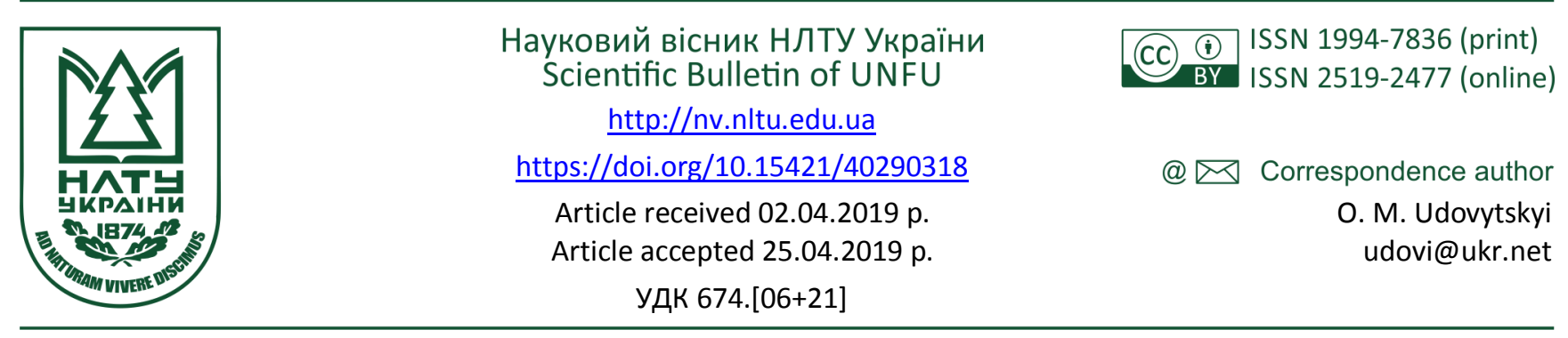

М. В. Удовицька', Л. О. Тисовський', В. О. Маєвський', О. М. Удовицький ${ }^{2}$

${ }^{I}$ Технологічний коледж Національного лісотехнічного університету України, м. Львів, Украӥна

${ }^{2}$ Національний лісотехнічний університет Украӥни, м. Львів, Украӥна

\title{
ДОСЛІДЖЕННЯ ФОРМОЗМІНИ ПИЛОМАТЕРІАЛІВ ДЛЯ ВИРОБНИЦТВА КЛЕЄНИХ ЩИТОВИХ КОНСТРУКЦЙ
}

\begin{abstract}
Переважна більшість досліджень клеєних конструкцій орієнтована на аналіз їхніх механічних характеристик, зокрема міцності та формостійкості. У випадку використання клеєної конструкції як елемента фасадної поверхні, важливого значення набувають також показники їі естетичності. Якість клеєних щитових конструкцій здебільшого зумовлена властивостями іiї окремих ділянок (заготовок, ламелей). Тому врахування властивостей цих ділянок сприятиме раціональному вибору схеми формування клеєних щитових конструкцій та прогнозуванню їх якості ще до склеювання ділянок у клеєних щитових конструкціях. У процесі експлуатації клеєні щитові конструкції можуть змінювати свою форму і розміри під впливом зовнішнього середовища. I чи не найважливішим чинником цього процесу є вологість, яка значно впливає на фізичні та механічні властивості деревини. Залежно від умов навколишнього середовища, деревина може як всихатися через виділення вологи, так і розбухати внаслідок вбирання вологи, призводячи до деформації пиломатеріалів. Отже, охарактеризовано основні причини можливої зміни форми поверхонь клеєних щитових конструкцій. Розроблено математичну модель для теоретичного дослідження формозміни пиломатеріалів. Одержані інженерні формули для розрахунку всихання і розбухання деревини свідчать, що формозміна пиломатеріалу переважно залежить від його розмірів, вологості та розташування у поперечному перетині колоди.
\end{abstract}

Ключові слова: зміна форми; всихання; розбухання; вологість деревини; розташування у поперечному перетині колоди.

Вступ. Одними $з$ поширених конструкційних елементів для виробництва різноманітних виробів 3 деревини є клеєні конструкції, зокрема й щитові (КЩК) (Ferents \& Maksymiv, 2011; Porter, 2001; Diachun, 2011). Такі клеєні конструкції здебільшого виготовляють 3 деревини або деревини, армованої різними матеріалами (металами, композитами чи полімерами) (García, Escamilla \& García, 2011; Surmai, 2015). Переважна більшість досліджень клеєних конструкцій орієнтована на аналіз їхніх механічних характеристик, зокрема міцності та формостійкості, та реалізовується експериментальним способом. Ці характеристики клеєних конструкцій зазвичай $\epsilon$ визначальними для встановлення їхньої якості та напрямів подальшої експлуатації. У випадку використання клеєної конструкції як елемента фасадної поверхні, важливе значення набувають також показники іiї естетичності (Maievskyi \& Beniakh, 2005; Pardaev, 2008; Maievskyi \& Udovytska, 2014).

Якість КЩК здебільшого зумовлена властивостями iï окремих ділянок (заготовок, ламелей). Тому врахування властивостей цих ділянок сприятиме раціональному вибору схеми формування КЩК та прогнозуван- ню їі якості ще до склеювання ділянок у КЩК. Використання такого підходу до виготовлення КЩК є актуальним, але малодослідженим.

Одним із перспективних шляхів вирішення питання щодо раціонального вибору схеми формування КЩК та прогнозування іiі якості до склеювання ділянок у КЩК $€$ розроблення математичного апарату для теоретичного дослідження формозміни пиломатеріалів. Такий математичний апарат повинен передбачати реалізацію послідовних інженерних розрахунків з урахуванням всихання або розбухання деревини різних порід залежно від зміни рівня вологості.

Постановка проблеми. Істотним недоліком виробів iз деревини $\epsilon$ те, що в процесі експлуатації вони можуть змінювати свою форму і розміри під впливом зовнішнього середовища. I чи не найважливішим чинником цього процесу є вологість, яка значно впливає на фізичні та механічні властивості деревини.

Деревина за своєю анатомічною будовою $є$ колоїдним та капілярно-пористим матеріалом (Bilei \& Pavliust, 2008), який через зниження вологості змінює свій об'єм пропорційно до кількості видаленої гігроскопіч-

\section{Інформація про авторів:}

Удовицька Мар'яна Володимирівна, викладач. Email: udovi@ukr.net

Тисовський Любомир Осипович, канд. фіз.-мат. наук, доцент, кафедра прикладної механіки. Email: tlo10@ukr.net Маєвський Володимир Олександрович, д-р техн. наук, професор, кафедра технологій лісопиляння, столярних і дерев'яних будівельних виробів. Email: mayevskyy_v@уаһoo.com

Удовицький Олександр Миколайович, канд. техн. наук, доцент, кафедра прикладної механіки. Email: udovi@ukr.net; https://orcid.org/0000-0003-2234-806X

Цитування за ДСТУ: Удовицька М. В., Тисовський Л. О., Маєвський В. О., Удовицький О. М. Дослідження формозміни пиломатеріалів для виробництва клеєних щитових конструкцій. Науковий вісник НлТУ України. 2019, т. 29, № 3. С. 85-88.

Citation APA: Udovytska, M. V., Tysovskyi, L. O., Mayevskyi, V. O., \& Udovytskyi, O. M. (2019). Research of form change of lumber for the manufacturing of laminated panels. Scientific Bulletin of UNFU, 29(3), 85-88. https://doi.org/10.15421/40290318 
ної вологи. Досить часто процес сушіння пиломатеріалу супроводжується зміною форми його поверхонь (деформацією), найчастіше спостерігаємо жолоблення за шириною пиломатеріалу. У пиломатеріалах із прямокутними поперечними перетинами (дошка, брус, брусок) жолоблення характеризується переміщенням країв пиломатеріалу на деяку величину в сторону опуклості річних кілець. Таке явище здебільшого зумовлене неоднорідністю всихання в радіальному і тангенціальному напрямках, а також залежить від положення пиломатеріалу в колоді, яке можна визначити за напрямком річних кілець на поверхнях пиломатеріалу.

У процесі експлуатації виробів із деревини, залежно від умов навколишнього середовища, деревина може як всихатися через виділення вологи, так і розбухати внаслідок вбирання вологи, призводячи до деформації пиломатеріалів. Це здебільшого зумовлено великою різницею між зміною розмірів у тангенціальному та радіальному напрямках, значення їхніх показників може відрізнятися навіть у 2 рази, залежно від породи деревини (Vintoniv, Sopushynskyi \& Taishinger, 2007; Wood Handbook, 2010). Процеси всихання та розбухання такого гігроскопічного матеріалу, як деревина, - предмет дослідження багатьох науковців. Результати їхніх досліджень засвідчують складну природу цих процесів, особливо зважаючи на анізотропність деревини.

Нехтування основними рекомендаціями щодо підбору ділянок деревини перед їхнім склеюванням у КЩК є однією з основних причин отримання низькоякісної, а в окремих випадках - і непридатної до подальшого використання продукції за показниками формостійкості.

Основний матеріал дослідження. Кількісними характеристиками всихання (радіального, тангенціального та аксіального) деревини $є$ відповідні коефіцієнти всихання, регламентовані нормативними документами, i характеризують зміну геометричних розмірів. Коефіцієнт всихання для різних напрямків можна визначити за формулою (Vintoniv, Sopushynskyi \& Taishinger, 2007)

$$
K=\frac{B c}{W_{0}-W_{1}} \cdot 100 \%,
$$

де: $B c$ - всихання у відповідному напрямку, $\%$; $W_{0}-$ початкова вологість, \%; $W_{1}$ - кінцева вологість, \%.

Оскільки предметом нашого дослідження $є$ зміна форми пиломатеріалу в поперечному перерізі, то розглядатимемо два коефіцієнти всихання: у радіальному $\left(K_{r}\right)$; та тангенціальному - $\left(K_{\tau}\right)$ напрямках. Всихання у поздовжньому напрямку незначне (Bilei \& Pavliust, 2008), тому ним нехтуємо. Коефіцієнти всихання пов'язані з лінійним всиханням у відповідному напрямку $\Delta$ співвідношеннями (Vintoniv, Sopushynskyi \& Taishinger, 2007):

$$
K_{r}=\frac{\Delta r}{r} \cdot 100 \% ; K_{\tau}=\frac{\Delta \tau}{\tau} \cdot 100 \%,
$$

де $\Delta r=r_{0}-\eta_{1} ; \Delta \tau=\tau_{0}-\tau_{1}-$ лінійне всихання пиломатеріалу в радіальному і тангенціальному напрямках відповідно; $r_{0}, \tau_{0}$ - лінійні розміри пиломатеріалу в радіальному і тангенціальному напрямках до всихання, мм; $\eta_{1}, \tau_{1}$ - лінійні розміри пиломатеріалу в радіальному і тангенціальному напрямках відповідно після всихання, мм.

Зазвичай напрямок ширини і товщини пиломатеріалу не збігаються ні з радіальним, ні з тангенціальним напрямами в поперечному перетині колоди, тому цей факт враховано під час розроблення математичної моделі. Розглянемо прямокутний перетин пиломатеріалу $\mathrm{ABCD}$, вирізаний із колоди з центром у точці О, припускаючи, що річні кільця мають форму концентричних кіл (рис. 1). Виберемо початок декартової системи координат у центрі круга i, не порушуючи загальності. Вважаємо, що координати вершин є такими: $A\left(x_{1}, y_{1}\right)$, $B\left(x_{1}, y_{2}\right), C\left(x_{2}, y_{2}\right), D\left(x_{2}, y_{1}\right)$, тобто ширина і товщина пиломатеріалу відповідно рівні $b=x_{2}-x_{1}\left(x_{2}>x_{1}\right), a=y_{2}-$ $y_{1}\left(y_{2}>y_{1}\right)$.

Лінійне всихання пиломатеріалу можна характеризувати переміщенням його точок і воно залежить не тільки від положення цих точок у конкретному перетині, але визначається і напрямком річних кілець. Тому лінійне всихання $є$ векторною величиною. Виберемо в перетині пиломатеріалу $\mathrm{ABCD}$ довільну точку $M\left(x_{0}, y_{0}\right)$. Тоді радіальне всихання $\vec{\Delta} r$ напрямлене по радіусу річного кільця від точки М до центра колоди, а вектор тангенціальної усушки $\vec{\Delta} \tau$ напрямлений по дотичній до річного кільця проти годинникової стрілки (в напрямку від осі $x$ до осі $y$ ).

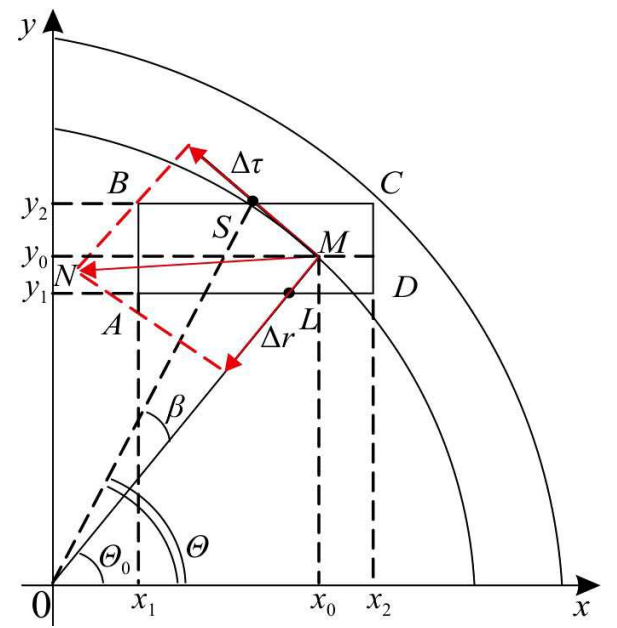

Рис. 1. Розрахункова схема до визначення лінійного всихання

Припустимо, що вологість пиломатеріалу зменшилася на величину $\Delta W: \Delta W=W_{1}-W_{2},\left(W_{2}<W_{1}<W *\right)$, де: $W_{2}$ - кінцева вологість; $W_{1}-$ початкова вологість; $W *$ - вологість, що відповідає точці насичення волокна, $(W *=30 \%)$. Під час процесу всихання точка $M$ переміститься у напрямку умовної точки $N(x, y)$, причому $\vec{M} N=\vec{\Delta}=\vec{\Delta} r+\vec{\Delta} \tau$, де: $\vec{\Delta}-$ сумарне зміщення точки $M$; $\vec{\Delta} \tau-$ зміщення точки $M$ у тангенціальному напрямку; $\vec{\Delta} r$ - зміщення точки $M$ у радіальному напрямку.

Враховуючи співвідношення (1), отримаємо:

$$
\begin{aligned}
& \Delta \tau=\frac{\cup M S \cdot K_{\tau} \cdot \Delta W}{100}=\frac{R \cdot \beta \cdot K_{\tau} \cdot \Delta W}{100} ; \\
& \Delta r=\frac{M L \cdot K_{r} \cdot \Delta W}{100}=\frac{\left(y_{0}-y_{1}\right) \cdot K_{r} \cdot \Delta W}{\sin \theta_{0} \cdot 100},
\end{aligned}
$$

де $R=\sqrt{x_{0}^{2}+y_{0}^{2}}$ - радіус річного кільця, на якому лежить точка $M ; \beta$ - центральний кут, на який спирається дуга $M S$; - кут, який утворює радіус-вектор точки $M 3$ додатнім напрямком осі $x ; \theta$ - кут, який утворює радіусвектор точки $S$ із додатнім напрямком осі $x$;

$$
\beta=\theta-\theta_{0} ; \theta_{0}=\operatorname{arctg} \frac{y_{0}}{x_{0}} ; \theta=\operatorname{arctg} \frac{y_{2}}{x_{*}} ; x_{*}=\sqrt{x_{0}^{2}+y_{0}^{2}-y_{1}^{2}} \text {. }
$$


Для того, щоб визначити величину вектора $\vec{\Delta}$, використаємо метод проекцій і спроектуємо вектори $\vec{\Delta} \tau$, $\vec{\Delta} r$ на осі вибраної системи координат. Тоді: $x=x_{0}-\Delta \tau \cdot \sin \theta_{0}-\Delta r \cdot \cos \theta_{0} ; \quad y=y_{0}+\Delta \tau \cdot \cos \theta_{0}-\Delta r \cdot \sin \theta_{0}$, або після перетворень:

$$
\left.\begin{array}{l}
x=x_{0}-\frac{\Delta W}{100}\left(\beta y_{0} K_{\tau}+\left(y_{0}-y_{1}\right) K_{r} \frac{x_{0}}{y_{0}}\right) \\
y=y_{0}+\frac{\Delta W}{100}\left(\beta x_{0} K_{\tau}-\left(y_{0}-y_{1}\right) K_{r}\right)
\end{array}\right\},
$$

де $\beta=\operatorname{arctg} \frac{y_{2}}{\sqrt{x_{0}^{2}+y_{0}^{2}-y_{1}^{2}}}-\operatorname{arctg} \frac{y_{0}}{x_{0}}$.

Отже, із співвідношень (2) випливає, що формозміна пиломатеріалу ABCD залежить від його розмірів, вологості (початкової та кінцевої) та розташування у поперечному перетині колоди, яке можна охарактеризувати кутами нахилу річних кілець.

Проаналізуємо математичні залежності (2):

1. Якщо $y_{0}=$ const, то отримаємо в параметричній формі рівняння кривої жолоблення для прямої, яка проходить через точку $M$ i паралельна до осі $x$. Параметром у цьому випадку є $x_{0} \quad\left(x_{1} \leq x_{0} \leq x_{2}\right)$.

Якщо $y=y_{1}$, то отримаємо рівняння нижньої пласті пиломатеріалу після всихання:

$$
x=x_{0}-\frac{\Delta W}{100} \beta y_{1} K_{\tau} ; y=y_{2}-\frac{\Delta W}{100} \beta x_{0} K_{\tau},
$$

де $\beta=\operatorname{arctg} \frac{y_{2}}{x_{0}}-\operatorname{arctg} \frac{y_{1}}{x_{0}}$.

Якщо $y=y_{2}$, то отримаємо рівняння кривої, в яку перейшла пряма $B C$ - верхня пласть після всихання:

$$
\begin{gathered}
x=x_{0}-\frac{\Delta W}{100}\left(\beta y_{2} K_{\tau}+\left(y_{2}-y_{1}\right) K_{r} \frac{x_{0}}{y_{2}}\right) \\
y=y_{2}+\frac{\Delta W}{100}\left(\beta x_{0} K_{\tau}+\left(y_{0}-y_{1}\right) K_{r}\right),
\end{gathered}
$$

де $\beta=\operatorname{arctg} \frac{y_{2}}{\sqrt{x_{0}^{2}+y_{2}^{2}-y_{1}^{2}}}-\operatorname{arctg} \frac{y_{2}}{x_{0}}$.

2. Якщо вважати, що $x_{0}=$ const, то залежності (2) можна розглядати параметричними рівняннями кривої формозміни за висотою пиломатеріалу. У цьому випадку параметром $€ y_{0} \quad\left(y_{1} \leq y_{0} \leq y_{2}\right)$.

Якщо $x=x_{1}$, то отримаємо рівняння кривої, в яку перейде відрізок АВ:

$$
\begin{gathered}
x=x_{1}-\frac{\Delta W}{100}\left(\beta y_{0} K_{\tau}+\left(y_{0}-y_{1}\right) K_{r} \frac{x_{1}}{y_{0}}\right) ; \\
y=y_{0}+\frac{\Delta W}{100}\left(\beta x_{1} K_{\tau}-\left(y_{0}-y_{1}\right) K_{r}\right),
\end{gathered}
$$

де $\beta=\operatorname{arctg} \frac{y_{2}}{\sqrt{x_{1}^{2}+y_{0}^{2}-y_{1}^{2}}}-\operatorname{arctg} \frac{y_{0}}{x_{1}}$.

Якщо $x=x_{2}$, то отримаємо рівняння кривої, в яку переходить відрізок $C D$ після всихання:

$$
\begin{gathered}
x=x_{2}-\frac{\Delta W}{100}\left(\beta y_{0} K_{\tau}+\left(y_{0}-y_{1}\right) K_{r} \frac{x_{2}}{y_{0}}\right) ; \\
y=y_{0}+\frac{\Delta W}{100}\left(\beta x_{2} K_{\tau}-\left(y_{0}-y_{1}\right) K_{r}\right),
\end{gathered}
$$

де $\beta=\operatorname{arctg} \frac{y_{2}}{\sqrt{x_{2}^{2}+y_{0}^{2}-y_{1}^{2}}}-\operatorname{arctg} \frac{y_{0}}{x_{2}}$.
Для дослідження формозміни пиломатеріалів, залежно від їхніх розмірів, вологості (початкової та кінцевої) та розташування у поперечному перетині колоди, проведено відповідні імітаційні дослідження з використанням отриманих математичних залежностей (2).

Для прикладу, наведемо графічні результати розрахунку формозміни соснового пиломатеріалу, зокрема набутої в змінних температурно-вологісних полях зі зміною (зменшенням) вологості $2 \%$ форми поверхні його верхньої та нижньої пластей (рис. 2). У розрахунках прийнято: розмір поперечного перетину пиломатеріалу $20 \times 150$ мм, пиломатеріал випиляно несиметрично відносно вертикальної осі $Y$ (див. рис. 1), коефіцієнти всихання (розбухання) $K_{r}=4,15, K_{\tau}=7,47$. Результати отриманих розрахунків (див. рис. 2) свідчать, що зміна вологості пиломатеріалу впливає на його формозміну. Зокрема, у наведеному випадку, максимальне відхилення верхньої та нижньої пластей, порівняно з початковими параметрими (до всихання), становить близько 0,24 мм для верхньої та 1,42 мм для нижньої пластей. Характер та величина формозміни пиломатеріалу узгоджується з результатами досліджень (Wood Handbook, 2010; Dahlblom, Ormarsson \& Petersson, 1996).

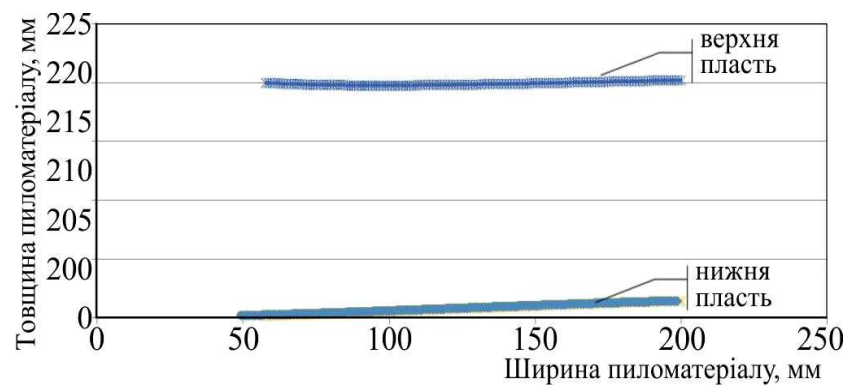

Рис. 2. Форма поверхні пластей пиломатеріалу

\section{Висновки:}

1. Розроблено математичний апарат для теоретичного дослідження формозміни пиломатеріалів, яка переважно залежить від його розмірів, вологості (початкової та кінцевої) та розташування у поперечному перетині колоди. Цей математичний апарат дає змогу реалізувати послідовні інженерні розрахунки форми поверхонь верхньої та нижньої пластей пиломатеріалу з урахуванням його експлуатації у змінних температурно-вологісних полях.

2. Результати імітаційного моделювання формозміни пиломатеріалу свідчать, що зміна вологості пиломатеріалу впливає на його формозміну. Зокрема, у наведеному випадку, максимальне відхилення верхньої та нижньої пластей, порівняно 3 початковими параметрими (до всихання), становить близько 0,24 мм для верхньої та 1,42 мм для нижньої пластей. Характер та величина формозміни пиломатеріалу узгоджується 3 результатами відомих досліджень.

\section{Перелік використаних джерел}

Bilei, P. V., \& Pavliust, V. M. (2008). Sushinnia i zakhyst derevyny. Lviv: National Forestry University of Ukraine, 312 p. [In Ukrainian].

Dahlblom, O., Ormarsson, S., \& Petersson, H. (1996). Simulation of wood deformation processes in drying andother types of environmental loading. Annales des sciences forestières, INRA/EDP Sciences, 53(4), 857-866.

Diachun, Z. Yo. (2011). Konstruiuvannia mebliv: Stoly, stiltsi ta krisla, mebli dlia vidpochynku. Vzaiemozaminnist, mitsnist, (part 2). Kyiv: Publishing House "Kyiv-Mohyla Academy", 484 p. [In Ukrainian]. 
Ferents, O. B., \& Maksymiv, V. M. (2011). Tekhnolohiia stoliarnykh vyrobiv. Lviv: NLTU Ukrainy, 400 p. [In Ukrainian].

García, P., Escamilla, A., \& García, M. (2011). Bending reinforcement of timber beams with composite carbon fiber and basalt fiber materials. Architectural Construction Department, School of Building Engineering, Polytechnic University of Madrid, (pp. 41-50). (Chapter 1). Spain.

Maievskyi, V. O., \& Beniakh, Yu. V. (2005). Doslidzhennia formostiikosti kleienykh shchytiv z masyvnoi derevyny duba. Scientific Bulletin of UkrSFU, 15(5), 199-208. [In Ukrainian].

Maievskyi, V. O., \& Udovytska, M. V. (2014). Osnovni napriamy doslidzhen u vyrobnytstvi kleienykh shchytovykh konstruktsii z derevyny iz dotrymanniam teksturnykh osoblyvostei. Scientific Bulletin of UNFU, 24(5), 150-155. [In Ukrainian].

Pardaev, A. S. (2008). Obespechenie formoustoichivosti neodnorodnykh massivov drevesiny s uchetom tcilindricheskoi anizotropii $i \mathrm{kh}$ elementov pri usushke i razbukhanii. Candidate dissertation for technical sciences (05.21.05 - Technology and Equipment of Woodworking Industries, Wood Science). Minsk. [In Russian].

Porter, B. (2001). Carpentry and Joinery. (3rd ed.). (Vol. 1), 694 p.

Surmai, M. I. (2015). Mitsnist ta deformatyvnist doshchatokleienykh balok armovanykh skloplastykovoiu ta bazaltovoiu armaturoiu. Candidate dissertation for technical sciences (05.23.01 - Building constructions, buildings and structures). Lviv, 185 p. [In Ukrainian].

Vintoniv, I. S., Sopushynskyi, I. M., \& Taishinger, A. (2007). Derevynoznavstvo. (2nd ed.). Lviv: Apriori, 312 p. [In Ukrainian].

Wood Handbook. (2010). Wood as on Engineering Material. Gen. Tech. Rep. FPL-GTR-190. Madison, WI: U. S. Department of Agriculture, Forest Service, Forest Products Laboratory, 508 p.

M. V. Udovytska1, L. O. Tysovskyi², V. O. Mayevskyí, , O. M. Udovytskyi ${ }^{2}$

${ }^{I}$ Technological College of the Ukrainian National Forestry University, Lviv, Ukraine

${ }^{2}$ Ukrainian National Forestry University, Lviv, Ukraine

\section{RESEARCH OF FORM CHANGE OF LUMBER FOR THE MANUFACTURING OF LAMINATED PANELS}

Laminated structures are one of the common structural elements for the manufacturing of various wood products. The vast majority of studies of laminated structures is focused on the analysis of their mechanical characteristics, in particular strength and shape stability. In the case of using a laminated structure as an element of the facade surface, the values of its aesthetics become important. The quality of laminated panels is mainly caused by the properties of its individual sections (bars, lamellae). Therefore, considering the properties of these sections will contribute to a rational choice of the scheme for the formation of a laminated panel and prediction of its quality before the gluing of sections in a laminated panel. One of the ways of solving the problem of rational choice of the scheme of forming laminated panels and predicting their quality before gluing is to develop a mathematical apparatus for the theoretical study of lumber form changing. In the process of exploitation laminated panels can change their shape and size under the influence of the external environment. The most important factor in this process seems to be humidity, which greatly affects the physical and mechanical properties of wood. Depending on the environment, wood may either dry out due to the release of moisture, or swell due to moisture absorption, resulting in deformation of lumber. Quantitative characteristics of wood drying are the corresponding drying coefficients that characterize the change in geometric sizes. The neglect of the main recommendations for the selection of wood sections before gluing them to the panel constructions is one of the main reasons for obtaining a low-quality, and in some cases, unsuitable for further use product. Thus, the article describes the main reasons for the possible change in the shape of the surfaces of laminated panels. A mathematical model for theoretical study of lumber change of form was developed. The resulting engineering formulas to calculate drying and swelling of wood indicate that the lumber change of form mainly depends on its size, moisture and location in the cross-section of the log.

Keywords: change of form; drying out; swelling; humidity of wood; location in the cross-section of the log. 